\title{
Rhetorical Strategies Used in the English Persuasive Essays of Indonesian University Students of EFL
}

\author{
Bambang Yudi Cahyono
}

\begin{abstract}
The purpose of this study was to investigate the use of rhetorical strategies in English persuasive essays written by Indonesian university students of English as a foreign language. This study also examined to what extent overall proficiency in English composition was predictive of the rhetorical strategies used in English persuasive essays. Two groups of undergraduate students were involved: the first- and fourth-year students in the English department of the State University of Malang, Indonesia. This study showed that that there was a statistically significant difference between the rhetorical strategies used in English persuasive essays written by the first- and fourth-year students. In general, the fourth-year students were more successful than the first-year students in using the superstructure of argument, the Toulmin model of informal reasoning, and the persuasive appeals. This study also showed that there was a positive significant correlation between the students' overall proficiency in English composition and the rhetorical strategies used in English persuasive essays.
\end{abstract}

Keywords: English persuasive essays, rhetorical strategies, superstructure of argument, the Toulmin model of informal reasoning, persuasive appeals, overall proficiency in English composition, ESL composition profile.

In the English Department of the State University of Malang, writing instruction is given through a series of writing courses: Writing I to Writing IV. Writing I emphasizes paragraph writing based on model paragraphs of various genres. Writing II teaches the students to develop ideas into an essay with an emphasis on the organization of the essay. Writing III provides the students with opportunities to write more essays with various techniques of development such as cause and effect or comparison and contrast. Writing IV focuses on the development of an argumentative type of writing, i.e. one with problem-solution patterns. Included in this advanced writing course is the instruction of the persuasive type of writing.

One of the types of discourses learned in these courses is the persuasive type. Research studies on persuasive rhetoric have involved native English writers (e.g., Connor \& Lauer's, 1988) and non-native English writers (e.g., Ferris, 1994).

Connor and Lauer (1988) studied English persuasive essays written by Englishspeaking students from three countries: the United States, England, and New Zealand. For this purpose, they developed measures used to evaluate English persuasive essays, which included the superstructure of argument, the Toulmin model of informal reasoning, and the persuasive appeals.

The superstructure of argument consists of four components: situation, problem, solution, and evaluation. The situation introduces the background for the statement of the problem. The problem is the undesirable state, while the solution is the desirable state. The evaluation analyzes the outcome of the suggested solution. The Toulmin model of informal reasoning consists of three parts, i.e. claim, data, and warrant. A 
claim is more widely known as the thesis statement. Data support the claim. Warrants are statements that lead to supporting inference. Persuasion requires the use of three appeals, i.e. rational, credibility, and affective. Rational appeals are arguments based on the structure of reality, such as example, illustration, model, analogy, and metaphor. The credibility appeals include the writer's personal experience, knowledge of the subject, and awareness of the audience's values. The affective appeals include the use of language with vivid pictures and metaphors to evoke emotion (Connor and Lauer, 1988).

Connor and Lauer found that it was difficult for the students to write persuasive compositions. They also found that the three measures were effective to evaluate persuasive essays written by students across cultural backgrounds.

Ferris (1994) investigated elements of English persuasive writing that appear to be particularly problematic for non-native speakers of English. Ferris analyzed 60 persuasive essays written by university composition students, half of who were native speakers and half of who were non-native speakers of English. The students' persuasive essays were examined in terms of quantitative counts, topical structure analysis, and the nature of rhetorical strategies.

In the quantitative analysis, the native speakers group outperformed the non-native speakers in the primary indicator of essay length, i.e. number of clauses. Native speakers were likely to have an advantage over non-native speakers in writing under timed conditions. In the topical structure analysis, the native speaker groups used a greater degree of topical focus than the non-native speaker groups. In the sentence type analysis, native speakers introduced the topical subject immediately at the beginning of the sentence, while non-native speakers were less likely to.

Ferris concluded that the native speakers' superiority in the three main variables may be caused by their greater degree of exposure to both oral and written English persuasive style. Conversely, the non-native speakers may have had only limited experience with English forms of persuasion, and the persuasive conventions of their own first language may be quite different from those used in English.

In preparation for the present study, it was difficult to find studies examining the rhetorical strategies used in English persuasive essays written by Indonesian learners of EFL. An attempt was made to review a few studies on rhetoric in EFL essays in the Indonesian context. Sulistyaningsih (1997) examined rhetoric in the expository essays of fourth-year university students majoring in English. It was found that many of the subjects wrote good thesis statements. Most of the paragraphs in the essays had good topic sentences. Among all of the developmental paragraphs, about three-quarters reflected the idea in the thesis statement. Most of the essays had good concluding paragraphs.

Latief (1990) examined the rhetorical quality of argumentative essays written by undergraduate students. The participants were students of the second, third, and fourth years. It was expected that each of the argumentative essays would show the position the writer was taking, provide at least one piece of relevant evidence, and show the relationship between the position taken and the evidence. It was found that the majority of the argumentative essays met the minimum acceptable quality and that the argumentative essays written by the fourth-year students were the best among the three other groups.

Ignatius (1999) investigated the features of English academic writing by graduate students of the English Department. The study revealed that in general the rhetorical structures of the essays reflected the overall feature of the English academic-writing essay. However, the rhetorical development of ideas in the essays did not entirely follow 
the linear staging of the information as expected by English-speaking readers. Many essays were marked by indirect approaches such as circular and digressive developments.

In light of the review of literature, it can be concluded that writing persuasive essays is not an easy task for both native and non-native English writers. Also, although Indonesian students of EFL are likely to know the rhetorical components of essays, the rhetorical development of ideas in their essays does not entirely conform to the expectations of English-speaking readers.

This study was aimed at evaluating the students' use of rhetorical strategies in English persuasive essays. The research questions were formulated as follows:

- In terms of rhetorical strategies, are there differences between the English persuasive essays written by the first- and fourth-year university students in the English Department?

- Is there any correlation between the students' use of rhetorical strategies in English persuasive essays and their overall proficiency in English composition?

\section{Methods}

The participants in this study were undergraduate students of the State University of Malang, Indonesia. Two groups of students were involved, i.e. the first- and fourthyear students. The first-year students were taking the intensive course program. The aim of the program is to develop the students' command of English to prepare them to take other courses offered in the department. In this program, language skills (listening, speaking, reading, and writing) and language elements (vocabulary, grammar, and pronunciation) are taught in an integrated manner. Writing exercises are mainly given at a sentence level. Above the sentence level, writing focuses on personalized expressions of experience, the purpose of which is to provide more opportunities for the students to write. The fourth year students had taken a series of writing courses: Writing I to IV as explained in the background of the study.

The two groups of students were asked to write persuasive essays on whether violence on TV programs should be restricted. The data collection took place in the first semester of 1999/2000 academic year. Prior to the actual data collection, a pilot study was conducted in two out of five classes of the first-year students. The purpose was to examine whether the prompt of the writing task had been understood. Two other classes of the first-year students and three classes of the fourth-year students were involved in the actual data collection. Forty essays from each group were selected randomly by using a table of random numbers. The essays from the pilot study were used in the practice session of scoring.

Connor and Lauer's model (1988) was applied to evaluate the use of rhetorical strategies in English and Indonesian persuasive essays. Following Connor and Lauer's procedures, student essays received one point for the presence of each the components of the superstructure of argument, i.e. situation, problem, solution, and evaluation (maximum score of 4). For the Toulmin model of informal reasoning, a score of 0-3 was given to each of the components of claim, data, and warrant (maximum score of 9). Like the procedures applied for the Toulmin model of informal reasoning, a score of 0-3 was given to each component of the persuasive appeals, that is the rational, credibility, and 
affective appeals (maximum score of 9). The total possible score for the use of rhetorical strategies was 22 .

The "ESL Composition Profile" (Jacobs, et al., 1981; Hartfiel, et al., 1985) was used to evaluate the students' overall proficiency in English composition. This profile divides writing into five components with various percentages, i.e. content (30\%), organization $(20 \%)$, vocabulary $(20 \%)$, language use $(25 \%)$ and mechanics $(5 \%)$. Each component has a set of criteria ranging from "excellent to very good" to "very poor" with a specified range of scores. The profile assumes 100 as the highest possible score.

The scoring of the persuasive essays was done by eight raters. All were faculty members of the English Department of the same university. Each rater had more than 12 years of experience in teaching English and in evaluating English compositions. Four scoring teams were formed, each consisting of two raters. Three teams scored the essays using one of the measures in Connor and Lauer's model. The fourth team scored the overall proficiency in English composition using the "ESL Composition Profile". Each rater scored 80 English essays.

To make sure that each of the measures was applied correctly in assigning scores for each essay, the raters were trained in workshop sessions. In the workshop sessions, the relevant measure and the procedures for applying this measure were first explained to the raters. The raters were asked to score five essays written by the students of the classes used in the pilot study. The raters read and scored the essays according to the criteria set for each measure. The scores of the raters were recorded and compared. Different scores were discussed in an attempt to arrive at agreement in the evaluation. At the end of discussion in each session, an agreement was finally reached for the overall scores and for the individual parts of the system as well. The interrater reliability for the rhetorical strategies in English essays was .91. It was found that the interrater reliability for the total scores of overall proficiency in English composition was .90 .

\section{Results}

The mean of rhetorical strategies used in the persuasive essays written by the firstyear students was 8.53 , while the mean of those used in the essays written by the fourthyear students was 13.30. Table 1 shows that the means of rhetorical strategies of the two groups of students were significantly different.

Table 1. Comparison of rhetorical strategies used in the persuasive essays (mean scores of 2 raters)

\begin{tabular}{lcccc}
\hline Group & $\mathrm{N}$ & Mean & SD & $t$ \\
\hline First-year students & 40 & 8.53 & 1.88 & $8.27^{*}$ \\
Fourth-year students & 40 & 13.30 & 3.13 & \\
\hline
\end{tabular}

$* \mathrm{p}<.05$

Further comparisons of rhetorical strategies used in the essays were based on the components of the superstructure of argument, the Toulmin model of informal 


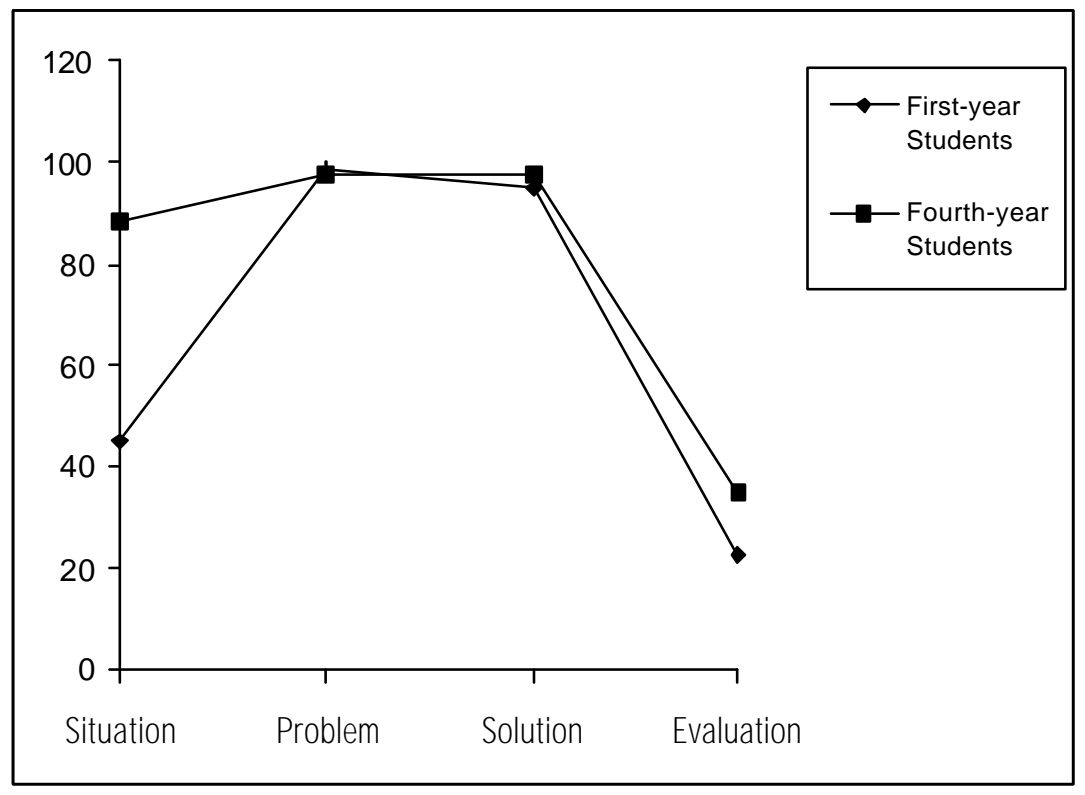

Figure 1.

Characteristics of the superstructure of argument

Table 3 compares the means of the components of the Toulmin model of informal reasoning used in the essays of the two groups of students. 
Table 3. Means of the components of the Toulmin model of informal reasoning (mean scores of 2 raters)

\begin{tabular}{lcccc}
\hline Group & $\mathrm{N}$ & Claim & Data & Warrant \\
\hline First-year students & 40 & 1.60 & 0.78 & 0.24 \\
Fourth-year students & 40 & 1.79 & 1.38 & 0.85 \\
\hline
\end{tabular}

Figure 2 shows the different characteristics of the Toulmin model of informal reasoning used in the essays written by the two groups of students. All three components of the Toulmin model of informal reasoning were more elaborated in the essays written by the fourth-year students than in those written by the first-year students.

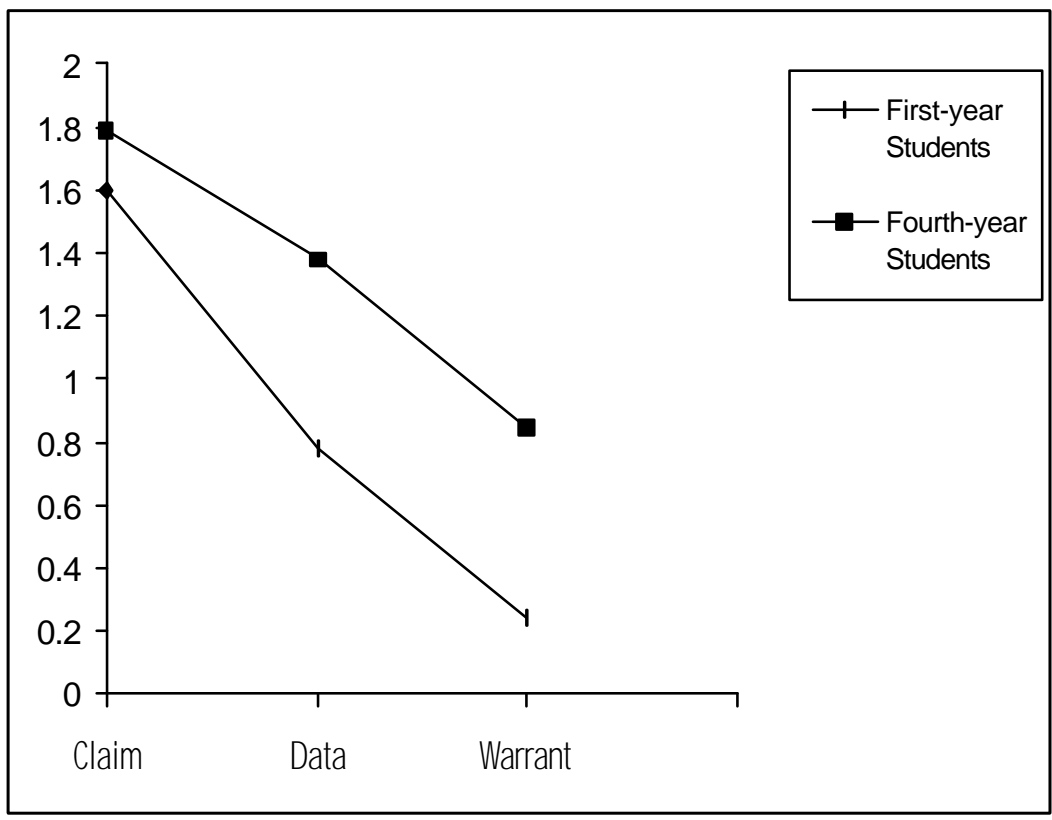

Figure 2.

\section{Characteristics of the Toulmin model of informal reasoning}

The essays of the first- and fourth-year students were somewhat similar in their characteristics of claims. The essays of both groups were likely to have explicitly stated claims with two or more subclaims that had been developed. In supporting the claim, the first-year students' essays were less likely to use data directly related to the major claims. On the other hand, the fourth-year students' essays tended to use some data with reliance on personal experience or authority. The first-year students hardly used warrants to relate data and claim in their essays, while the fourth-year students used warrants which were minimally reliable and relevant to the claim.

The mean scores for rational, credibility and affective components of the persuasive appeals are presented in Table 4. 
Table 4. Means of the components of the persuasive appeals (mean scores of 2 raters)

\begin{tabular}{lcccc}
\hline Group & $\mathrm{N}$ & Rational & Credibility & Affective \\
\hline First-year students & 40 & 1.28 & 1.18 & 0.88 \\
Fourth-year students & 40 & 2.28 & 1.99 & 1.85 \\
\hline
\end{tabular}

Figure 3 shows substantial differences in the use of persuasive appeals in the essays written by the first- and fourth-year students. In general, the fourth-year students were more successful in using the persuasive appeals than the first-year students.

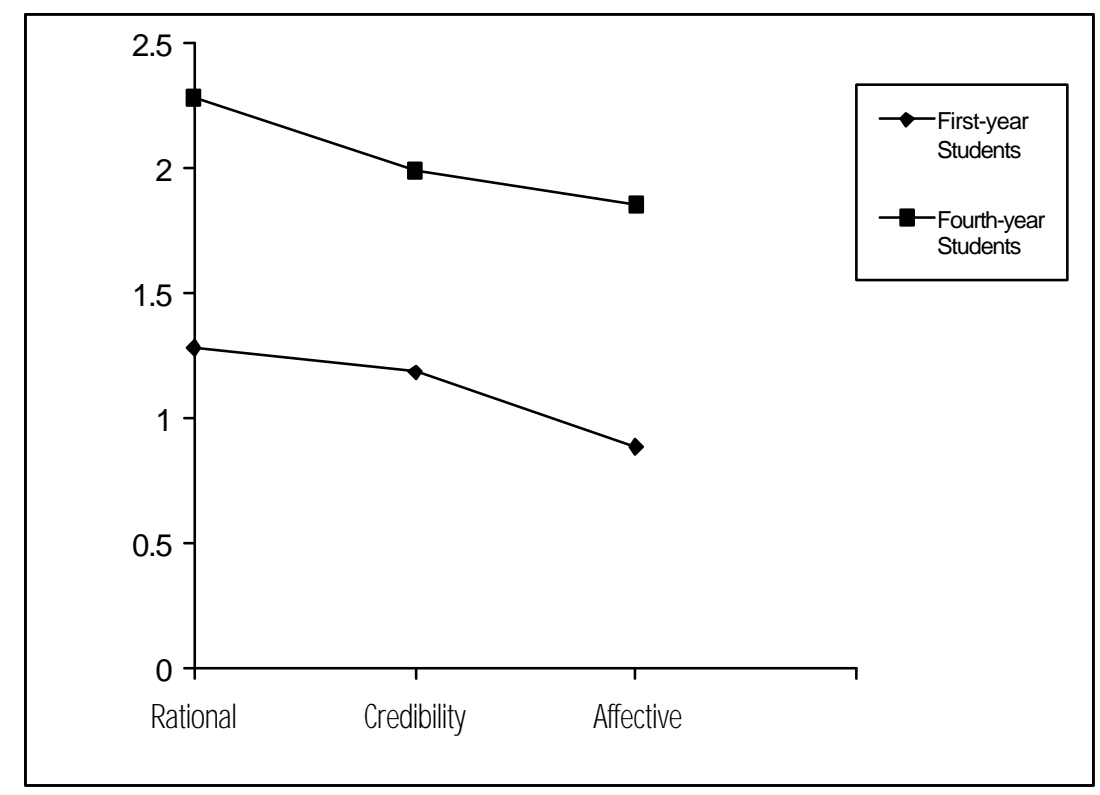

Figure 3.

Characteristics of the persuasive appeals.

The essays written by the first-year students rarely used rational appeals. In contrast, the essays written by the fourth-year students used a single (or a series of) rational appeal(s) with at least two points of development. The credibility component suggested that the first-year students' essays were likely to show some writer credibility or some awareness of audience's values. Conversely, the fourth-year students' essays clearly showed some writer credibility and some awareness of audience's values. Regarding the affective appeal, the first-year students' essays rarely used charged language or metaphors to evoke emotion, whereas the fourth-year students' essays adequately used charged language or metaphors to evoke emotion.

The mean of overall proficiency in English composition of the first-year students is 65.33 , while that of the fourth-year students is 84.36 . Table 5 shows that there is a significant difference between overall proficiency in English composition of the first- and fourth-year students. 
Table 5. A comparison of overall proficiency in English composition (mean scores of 2 raters)

\begin{tabular}{lcccc}
\hline Group & $\mathrm{N}$ & Mean & SD & $t$ \\
\hline First-year students & 40 & 65.33 & 12.04 & -7.92 \\
Fourth-year students & 40 & 84.36 & 9.30 & \\
\hline
\end{tabular}

$* \mathrm{p}<.05$

Since it was already known that there were significant differences between first- and fourth-year students' use of rhetorical strategies and their overall proficiency in English composition, the correlation between overall proficiency and rhetorical strategies was carried out within groups.

It was found that there was a significant positive correlation between the first-year students' use of rhetorical strategies in persuasive essays and their overall proficiency in English composition $r=.55, \mathrm{df}=38, \mathrm{p}<0.05)$. There was a significant positive correlation between the fourth-year students' use of rhetorical strategies in persuasive essays and their overall proficiency in English composition $(r=.71, \mathrm{df}=38, \mathrm{p}<0.05)$. The students who scored high on the overall proficiency in English composition tended to have higher scores on the use of rhetorical strategies.

\section{Discussion}

The rhetorical strategies used in English persuasive essays written by the first-year students differed significantly from the rhetorical strategies used in English persuasive essays written by the fourth-year students in the English department. This difference might be attributed to the role of instruction. When the study was carried out, the firstyear students were still in the beginning stages of their university study, taking the intensive course program. In general, the first-year students' lack of skills was considered as the reason for the difference. On the other hand, the fourth-year students had taken most of their university courses and a series of university-level writing courses. These writing courses taught the students to write paragraphs and essays, including the persuasive type of discourse. It was likely that writing instruction affected the students' use of rhetorical strategies in persuasive writing.

There was a significant positive correlation between the English students' use of rhetorical strategies in persuasive essays and their overall proficiency in English composition. The development of the students' skills in using rhetorical strategies in persuasive essays was likely to go along with the development of their writing ability. The ability to use the superstructure of argument, claims and supports, and charged language and metaphors is significantly related to the ability to elaborate the contents, to organize the ideas, and to choose and use vocabulary in essays. Furthermore, as shown by the difference in the coefficients of the first- and the fourth-year students, the proficiency level of the students appeared to determine the strength of the relation. This implies that success in using rhetorical strategies in persuasive essays and in overall proficiency in English composition was likely to follow the development of the students' proficiency in learning English. Again, instruction appeared to contribute to the development of the students' ability to use rhetorical strategies and their overall proficiency in English composition as well. 


\section{Conclusions}

In light of the results of the study and the discussion of the results, two conclusions can be drawn. First, instruction appeared to play a role in developing the students' performance in using rhetorical strategies in writing English persuasive essays and in overall proficiency in English composition. This implies that the instructional program provided for the students in the English department had successfully led them to a better performance in writing EFL in general and in writing English persuasive essays in particular. Second, overall proficiency in English composition was a good predictor of success in using rhetorical strategies in English persuasive essays.

\section{References}

Connor, U., \& Lauer, J. (1988). Cross-cultural variation in persuasive student writing. In A.C. Purves (Ed.), Writing across languages and cultures: Issues in contrastive rhetoric. Newbury Park, CA: Sage. 138-159.

Ferris, D.R. (1994). Rhetorical strategies in student persuasive writing: Differences between native and non-native English speakers. Research in the Teaching of English, 28, 45-65.

Hartfiel, V.F., Jacobs, H.L., Zinkgraft, S.A., Wormuth, D.R., \& Hughey, J.B. (1985). Learning ESL composition. Rowley, MA: Newbury House.

Ignatius, H. (1999). English academic writing features by Indonesian learners of English. Dissertation. Graduate Program of the State University of Malang, Indonesia.

Jacobs, H.L., Zinkgraf, S.A., Wormuth, D.R., Hartfiel, V.F., \& Hughey, J.B. (1981). Testing ESL composition: A practical approach. Rowley, MA: Newbury House.

Latief, M.A. (1990). Assessment of English writing skills for students of English as a foreign language at the Institute of Teacher Training and Education IKIP MALANG Indonesia. Dissertation. Iowa: The University of Iowa.

Sulistyaningsih. (1997). A descriptive study on rhetoric in students' expository essays. Thesis. Malang: English Department of the State University of Malang, Indonesia. 